\title{
Renal Parenchymal Hypoxia, Hypoxia Response and the Progression of Chronic Kidney Disease
}

\author{
Samuel N. Heyman ${ }^{a} \quad$ Mogher Khamaisi $^{\mathrm{a}} \quad$ Seymour Rosen ${ }^{\mathrm{b}}$ \\ Christian Rosenberger ${ }^{\mathrm{c}}$ \\ ${ }^{a}$ Departments of Medicine, Hadassah Hospitals, Mt. Scopus and Ein Kerem and Hebrew University Medical School, \\ Jerusalem, Israel; ${ }^{b}$ Department of Pathology, Beth Israel Deaconess Medical Center and Harvard Medical School, \\ Boston, Mass., USA; ' Nephrology and Medical Intensive Care, Charité University Clinic, Berlin, Germany
}

\section{Key Words \\ Hypoxia, renal parenchymal • Chronic kidney disease • Oxygenation, renal tissue}

\section{Abstract}

Renal parenchymal hypoxia, documented under a variety of clinical conditions, conceivably contributes to the progression chronic kidney disease. In this review, normal physiologic medullary hypoxia and abnormal profiles of renal $\mathrm{pO}_{2}$ in chronic kidney diseases are presented, and the mechanisms leading to anomalous renal tissue oxygenation are discussed. Direct measurements of $\mathrm{pO}_{2}$ with oxygen electrodes, immunostaining with pimonidazole (which binds to regions with very low $\mathrm{pO}_{2}$ ), or the detection of hypoxia-inducible factor (HIF)- $\alpha$ (which accumulates in hypoxic regions, initiating hypoxia-adaptive responses), all serve to detect the distribution and extent of renal parenchymal hypoxia under experimental settings. The use of BOLD MRI as a noninvasive tool, detecting deoxygenated hemoglobin in hypoxic renal tissues, has evolved from experimental settings to human studies. All these modalities indicate that abnormal renal oxygenation develops under conditions such as chronic glomerular, tubulointerstitial or renovascular disease, in diabetes, hypertension, aging, renal hypertrophy, anemia or obstructive uropathy. Abnormal renal tissue
\end{abstract}

\section{KARGER}

Fax +41613061234

E-Mail karger@karger.ch

www.karger.com
(C) 2008 S. Karger AG, Basel

0250-8095/08/0286-0998\$24.50/0

Accessible online at:

www.karger.com/ajn hypoxia modifies the pattern of regional gene expression, evoking a host of adaptive and renoprotective pathways (such as HIF-mediated erythropoietin or heme-oxygenase1), in parallel with the induction of potentially harmful mediators that participate in the progression of chronic kidney injury. Slowing the progression of chronic kidney disease may be achieved by a better understanding of these parallel processes and the accomplishment of a selective control of such protective and maladaptive responses.

Copyright $\odot 2008$ S. Karger AG, Basel

\section{Introduction}

Kidney function, determined as the glomerular filtration rate (GFR), declines at a rate of about $1 \mathrm{ml} / \mathrm{min}$ per year. In patients with chronic kidney disease (CKD), the rate of decline in GFR is accelerated and may reach over $10 \mathrm{ml} / \mathrm{min}$ per year.

This review, presented in part at the International Society of Nephrology meeting, Rio de Janeiro, 2007, was supported by a grant from Russell Berrie Foundation and D-Cure, Diabetes Care in Israel, and by the Harvard Medical Faculty Physicians at Beth Israel Deaconess Medical Center, Boston, Mass., USA.
Dr. S. Heyman

Department of Medicine, Hadassah Hospital, Mt. Scopus

PO Box 24035

IL-91240 Jerusalem (Israel)

Tel. +972 258441 11, Fax +972 258235 15, E-Mail Heyman@cc.huji.ac.il 
Fig. 1. Renal medullary oxygen balance. The renal medulla normally functions under hypoxic conditions, reflecting limited oxygen supply, barely sufficient for intense regional oxygen consumption for tubular transport. Low oxygen delivery results from limited blood supply and oxygen diffusion from descending to ascending vasa recta (illustrated in inset). Regional oxygen consumption is governed by factors affecting the extent of solute delivery for distal tubular reabsorption, as well as to the control of transport activity. VR = Vasa recta; GFR = glomerular filtration rate; $\mathrm{PT}=$ proximal tubules .
Outer medullary oxygen balance

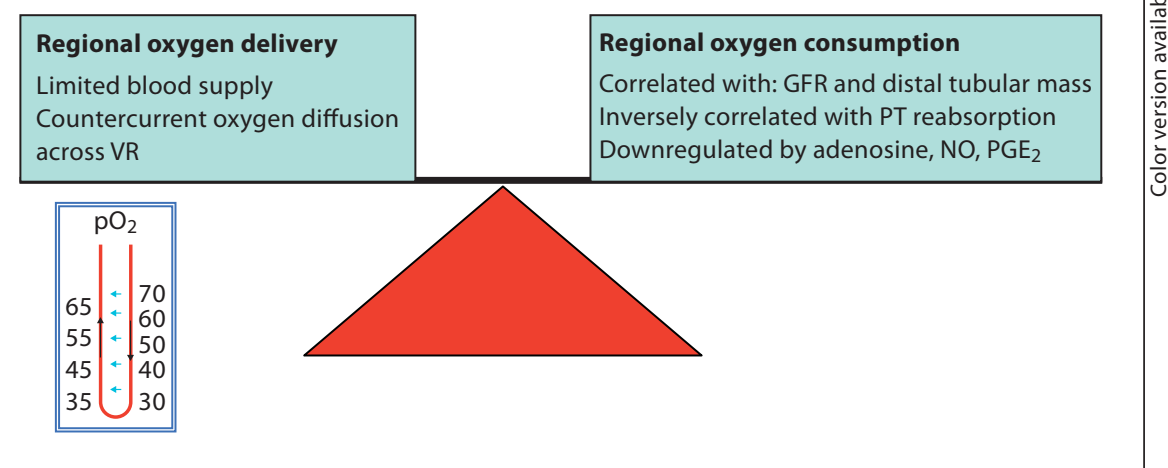

In the 1980s, Brenner et al. $[1,2]$ suggested that altered glomerular hemodynamics govern the accelerated progression of chronic renal failure (CRF). They assumed that an initial reduction in renal cell mass leads to a 'wear and tear' phenomenon, with glomerular hypertension, hyperfiltration, and hypertrophy of functioning glomeruli, ultimately ending with glomerular sclerosis, glomerular dropout, and the generation of an ongoing vicious circle of progressive renal damage.

The major flaw in this hypothesis is that in patients with chronic renal disease the extent of renal dysfunction poorly associates with changes in glomerular morphology, whereas it correlates well with chronic tubulointerstitial injury [3]. This has shifted the interest to multiple other factors, including proteinuria and associated interstitial cytokine release, in the progression of CKD [4]. Numerous studies have underlined the importance of oxygen free radicals, vasoactive substances, tubular hypertrophy, hypermetabolism, and endothelial dysfunction, but noteworthy, until 1998 the word 'hypoxia' was still missing in graphic illustrations of this complex pathophysiology [5].

In 2000, Fine et al. [6] pointed out that inhibitors of the renin-angiotensin-aldosterone axis slow the progression of CRF regardless of the control of hypertension or the presence or absence of proteinuria. Their review forms the basis for a new evolving concept on the role of hypoxia in the progression of CKD. They proposed that kidney injury leads to a vicious circle of tissue fibrosis, pursuant obliteration of the renal microvasculature, hypoxia and continued damage [6].

Indeed, renal parenchymal hypoxia has been consistently documented by currently available technologies. Regional renal microcirculation and $\mathrm{PO}_{2}$ can be continu-

Renal Parenchymal Hypoxia, Hypoxia

Response and Progression of CKD ously monitored under experimental settings with needle-laser Doppler flow probes and with oxygen microelectrodes, respectively. The distribution of renal parenchymal hypoxia and hypoxia adaptive responses can now be mapped using immunostaining for pimonidazole (molecular 'hypoxia probe' which, following injection, binds to tissues with oxygen tension below $10 \mathrm{~mm} \mathrm{Hg}$ ) and for hypoxia-inducible factors (HIF; see below). Finally, blood oxygenation level-dependent (BOLD) MRI provides a noninvasive measure to determine the dynamic changes in the distribution and extent of deoxygenated hemoglobin within the renal parenchyma. Based on these technologies, we shall appraise the evidence for renal parenchymal hypoxia under conditions that predispose to accelerated progression of $\mathrm{CKD}$, providing insight into potential interventional measures in efforts to retard the decline in kidney function.

\section{Renal Oxygen Profile: The Nature of Renal Medullary Hypoxia}

Renal parenchymal oxygenation reflects the balance between regional oxygen supply and oxygen consumption, principally for tubular transport $[7,8]$. Oxygen demand is governed by GFR, by tubular and ion-pump mass, and by various regulators that control transport activity. Oxygen supply mirrors systemic and intrarenal factors that control intrarenal blood flow and distribution, the oxygen-carrying capacity of the blood, and the specific structure of the renal microcirculation. Peritubular capillaries are nourished by efferent glomerular arterioles. Efferent arteriolar $\mathrm{PO}_{2}$ is lower than renal venous $\mathrm{PO}_{2}$, implying cortical precapillary shunting that 
Fig. 2. The control of renal medullary oxygen balance. Medullary oxygen sufficiency is maintained by matching regional oxygen supply and demand. Tight control of these factors is maintained by various mediators, including nitric oxide (NO), prostaglandins (mainly $\mathrm{PGE}_{2}$ ) and adenosine, which increase medullary blood flow and downregulate tubular transport. Importantly, suppression of GFR, in part through moderate cortical vasoconstriction, reduces solute delivery for distal tubular reabsorption and subsequent oxygen consumption. Some of these control systems are hampered in CKD, for instance singlenephron GFR is increased, or regional NO and $\mathrm{PGE}_{2}$ synthesis are faulted. Reactive oxygen species (ROS) also interfere in this delicate balance, by causing endothelial dysfunction and through dis-inhibition of tubular transport.

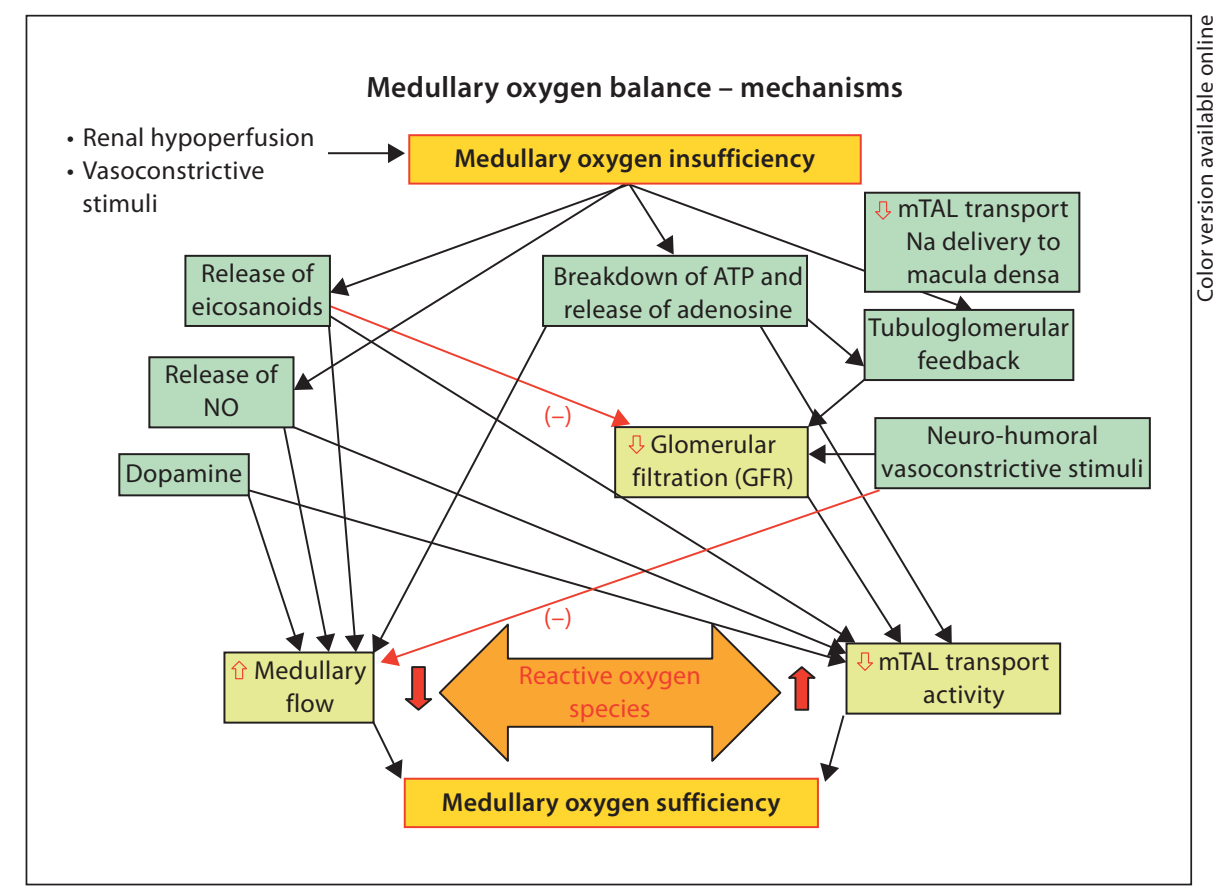

leads to renal parenchymal hypoxia [9]. Furthermore, a non-homogenous distribution of renal parenchymal oxygenation exists, with renal parenchymal $\mathrm{pO}_{2}$ sharply declining at the cortico-medullary junction, reaching levels as low as $25 \mathrm{~mm} \mathrm{Hg}$ within the renal medulla under normal physiologic conditions $[7,10]$. This physiologic hypoxia of the renal medulla stems from limited oxygen supply, barely sufficient for ample regional oxygen consumption (fig. 1). The medulla receives some $10 \%$, only, of total renal blood flow originating from efferent arterioles of deep juxtamedullary glomeruli. These blood vessels merge to form vascular bundles (vasa recta), a central component of the renal concentrating machinery. Importantly, the unique architecture of a countercurrent blood flow in vasa recta facilitates oxygen diffusion from descending to ascending blood vessels and contributes to reduced oxygen availability to the medulla. At the same time, the outer medullary oxygen requirement for tubular transport by medullary thick ascending limbs (mTALs) and S3 (straight) segments of the proximal tubules is intense. Complex mechanisms participate in the preservation of renal medullary oxygen sufficiency, by the control and matching of both intrarenal blood flow and tubular transport activity (fig. 2). Prostaglandins (principally $\mathrm{PGE}_{2}$ ), nitric oxide, adenosine and other mediators act in concert to maintain this oxygenation balance by enhancement of medullary blood flow and sup- pression of tubular transport. Reduction of GFR is one of the mechanisms that maintain medullary oxygenation by reducing solute delivery for reabsorption in the distal nephron. It is noteworthy that reactive oxygen species (ROS) undermine these protective mechanisms, compromising ambient microcirculation and counteracting mechanisms that attenuate tubular transport $[7,8,10]$.

Changes in medullary oxygenation following the administration of non-steroidal anti-inflammatory agents illustrate the importance of the protective mechanisms mentioned above: regional medullary blood flow (determined by laser Doppler probes) acutely declines and tubular transport is enhanced, leading to a substantial fall in ambient oxygenation over a protracted period of time [11, 12]. Evidently, chronically intensified medullary hypoxia underlies the pathophysiology of analgesic nephropathy, characterized by medullary fibrosis and papillary necrosis.

\section{Renal HIF during Hypoxic Stress}

Chronic tissue hypoxia invokes a hypoxic response, mediated to large extent by HIFs [10, 13-15]. These ubiquitous key transcription factors consist of $\alpha$ - and $\beta$-subunits. The $\alpha$-subunit is rapidly degraded and removed under normal ambient oxygenation by specific oxygen- 
sensitive prolyl hydroxylases. Hypoxia inactivates the degradation of HIF- $\alpha$ by these enzymes, and it accumulates and binds with the $\beta$-subunit. The formed heterodimer translocates into the nucleus, binds to hypoxia-response elements and activates a host of HIF-mediated genes that participate in cell adaptation to hypoxia. There are over 100 genes known to be mediated by HIF, which control cell metabolism and survival, angiogenesis, vascular tone, and tissue oxygenation. Heme oxygenase-1, erythropoietin, and VEGF are among the long list of HIF-mediated cytoprotective genes.

There are at least two HIF- $\alpha$ isoforms. Renal HIF is cell-type specific with HIF-1 $\alpha$ isoform principally expressed in tubular segments (mostly in collecting ducts), while HIF- $2 \alpha$ is detected in vascular endothelial and interstitial cells. Genes expressed by HIF are also cell- and locus-specific, for instance, erythropoietin is selectively induced by interstitial cells at the cortico-medullary junction [16]. Not surprisingly, this region, functioning on the verge of hypoxia, serves in the control of the blood oxygen-carrying capacity.

Using immunostaining for both pimonidazole and HIF, as well as for the expression of HIF-mediated genes, we have recently mapped the extent and distribution of renal hypoxia under acute settings, such as global renal hypoxia or intrarenal regional vascular obliteration, following the administration of non-steroidal anti-inflammatory or radiocontrast agents, during the induction of hypoxic acute renal failure or following rhabdomyolysis [17-20]. With these methods applied at different intervals after insults we could detect the spatial and chronological evolution and recovery of localized intrarenal critical hypoxia, and the pursuant induction of the HIF-mediated hypoxic response.

\section{Mechanisms for Intensified Renal Hypoxia in CKD}

CKD is characterized by intensified renal hypoxia. Using BOLD MRI, Manotham et al. [21] noticed the enhanced concentration of deoxygenated hemoglobin within the medulla (i.e. intensified regional hypoxia) in humans with CKD as compared with control healthy kidneys. Interestingly, medullary hypoxia has been attenuated following the administration of an angiotensin II (AII) receptor antagonist. These observations illustrate that AII plays an important role in the generation of renal hypoxia in CKD [22]. BOLD MRI may also identify whole-kidney or segmental renovascular disease affecting parenchymal oxygenation. Importantly, in these set- tings BOLD MRI may distinguish between severely compromised but viable parenchyma (high basal values of deoxygenated hemoglobin, falling after the administration of furosemide) and non-functional scar tissue (low basal levels, unaffected by furosemide) [23].

Basile et al. [24] showed that chronic tubulointerstitial disease also leads to depletion of peritubular capillaries, illustrated by microfil infusion into rat kidneys $4-8$ weeks after ischemia/reperfusion injury. In this model the capillary volume and perfusion index fall in all renal regions along time, meaning less oxygen supply. Furthermore, evolving fibrosis and the deposition of extracellular matrix interferes with ambient oxygen diffusion [24]. As the peritubular capillaries originate from efferent glomerular arterioles, it is noteworthy that primary glomerular diseases with obliteration of glomerular capillaries also compromise downstream peritubular microcirculation and intensify parenchymal hypoxia $[25,26]$.

Nephron depletion per se may intensify renal hypoxia: uninephrectomy results in the expression of pimonidazole adducts in the remaining kidney, evidence of intense hypoxia, conceivably reflecting hypertrophy, enhanced GFR and increased tubular transport [27]. Similarly, pimonidazole immunostaining is more pronounced following uninephrectomy in a model of experimental nephritis, characterized by peritubular capillary depletion, fibrosis, and inflammation [25].

In an experimental model of chronic tubulointerstitial disease induced by ischemia-reflow injury, regions with depleted renal microvasculature and expanded extracellular matrix display deposition of pimonidazole, indicating critical hypoxia, as well as HIF expression, reflecting a cellular response to hypoxia [28]. Similar indices of evolving hypoxia were noted in other animal models of hypoxic/nephrotoxic tubulointerstitial disease induced by adriamycin, cyclosporine A and folic acid [29-31]. Both pimonidazole and HIF immunostaining are more pronounced in kidneys with moderate tubulointerstitial changes, as compared with severely damaged kidneys [28]. Possibly this has to do with a more pronounced reduction in GFR in the more injured kidneys, with subsequent lower oxygen consumption for tubular transport. Thus, the distorted anatomy of CKD can augment hypoxia, but with extreme loss of functional tissue this hypoxic condition may diminish.

Aging is also associated with intensified renal hypoxia. As shown by BOLD MRI, ambient $\mathrm{pO}_{2}$ is some $20 \mathrm{~mm}$ $\mathrm{Hg}$ lower both in the cortex and the medulla in otherwise healthy aged individuals, as compared with tracings undertaken in young subjects [32]. Hypoxia and hypoxia 
adaptation were also noted in aged rat kidneys, using immunostaining for pimonidazole, HIF and HIF-mediated genes [33]. This may reflect the reduced capacity of the aged kidney to generate nitric oxide and $\mathrm{PGE}_{2}$ [34-36].

Diabetes also predisposes to renal parenchymal hypoxia, as shown by Palm et al. [37] using oxygen microelectrodes in rats. The decline in parenchymal oxygenation in the diabetic kidney is most pronounced in the medulla, and principally reflects enhanced tubular transport. Renal oxygenation in the diabetic kidney is restored by the administration of antioxidants, which scavenge ROS and normalize transport activity. Medullary hypoxia in the diabetic rat kidney has also been documented using BOLD MRI $[38,39]$ and with pimonidazole and HIF immunostaining [40]. These indices of medullary hypoxia disappear with the control of hyperglycemia. Interestingly, though hypoxia is ameliorated [37], HIF expression intensifies with the addition of a ROS scavenger [40], suggesting that ROS suppresses hypoxic adaptive responses. These findings are in agreement with studies in cultured proximal tubular cells and in diabetic rats, showing oxidative stress-regulated attenuation of the HIF-VEGF pathway [41].

Thus, the role of hypoxia in the progression of injury in the diabetic kidney is now well acknowledged [42] to be induced by oxidative stress and ROS, by altered renal hemodynamics (in part through altered nitrovasodilation [43]), inflammation and fibrosis. Hypoxia may also be enhanced by increased GFR, tubular hypertrophy and transport activity.

Hypertension may also lead to renal hypoxia, as determined with oxygen microelectrodes in hypertensive rats [9]. Intensified hypoxia in these animals reflects enhanced oxygen demand due to defective coupling of tubular transport and oxygen consumption. As with diabetes, ROS is considered to contribute to reduced renal blood flow and to an inefficient use of oxygen for sodium transport [44].

Chronic salt and volume depletion may invert the normal renal oxygenation gradient: under such experimental conditions cortical $\mathrm{pO}_{2}$ declines, representing decreased total renal blood flow and vasoconstrictive stimuli, whereas medullary oxygenation paradoxically improves [45]. The attenuated medullary hypoxia conceivably reflects decreased tubular transport due to reduced GFR, enhanced proximal tubular reabsorption, mTAL atrophy and cortico-medullary redistribution of renal blood flow.

Hypoxia may also exist in transplanted kidneys, as shown by HIF immunostaining in human renal trans-
Table 1. Postulated mechanisms responsible for declining renal oxygenation in CKD

\section{Decreased oxygen supply}

Peritubular capillary loss

Interstitial fibrosis

Glomerular sclerosis and a decline in downstream peritubular flow

Anemia

Altered vascular tone

Decreased nitric oxide and prostaglandin synthesis

Enhanced vasoconstrictive stimuli: AII-induced efferent arteriolar vasoconstriction; enhanced endothelin-1 Oxidative stress

\section{Increased oxygen consumption}

Tubular hypertrophy and enhanced GFR in remnant nephrons Repeated transiently enhanced GFR (high-protein meals) Oxidative stress-related dis-inhibition of tubular transport

plants, especially during cellular rejection [46]. However, BOLD MRI studies disclosed contradictive findings, where medullary physiologic hypoxia was attenuated in rejected kidneys [47]. Differences in the magnitude of GFR decline and subsequent attenuation of transport activity might explain these discrepancies.

Low hematocrit also results in decreased oxygen supply to the kidney. As shown with oxygen microelectrodes inserted into the kidney during acute decrements in hematocrit, both cortical and medullary $\mathrm{pO}_{2}$ decline [48]. Renal parenchymal HIF accumulation appears under comparable conditions, such as exposure of the animal to carbon monoxide [17].

BOLD MRI experimental studies indicate that urinary outflow obstruction results in reduced cortical oxygenation, while medullary $\mathrm{pO}_{2}$ increases [49]. Conceivably, this reflects a renovascular response to obstruction, with reduced cortical blood flow and GFR, with a subsequent reduced distal tubular transport activity.

Finally, renal hypoxia in CKD may hypothetically reflect additional causes for enhanced oxygen consumption: ineffective proximal tubular work could shift reabsorption to more distal tubular sites where ATP and oxygen costs may be higher. Additional metabolic workload and oxygen consumption might be related to gluconeogenesis, to reabsorption and degradation of excessively filtered proteins or to chemical utilization of oxygen via activation of various kidney oxidases. The quantitative contribution of such putative mechanisms in the evolution of renal hypoxia in CKD remains speculative. 
Table 2. Studies [reference numbers] giving evidence of renal hypoxia in CKD and in conditions predisposing to CKD

\begin{tabular}{|c|c|c|c|c|c|c|}
\hline \multirow[t]{2}{*}{ Clinical setup } & \multicolumn{2}{|c|}{ Study type } & \multirow[t]{2}{*}{ BOLD MRI } & \multirow{2}{*}{$\begin{array}{l}\text { Oxygen } \\
\text { electrodes }\end{array}$} & \multicolumn{2}{|c|}{ Immunostaining } \\
\hline & animal & human & & & PIM & $\begin{array}{l}\text { HIF-medi- } \\
\text { ated genes }\end{array}$ \\
\hline Tubulointerstitial disease & J & $\sqrt{ }$ & 21 & & 28,30 & 28,29 \\
\hline Primary glomerulopathy & $\sqrt{ }$ & & & & 25 & 25 \\
\hline Nephrotoxic CKD & $\sqrt{ }$ & & & & 30 & 29 \\
\hline Renal mass depletion & $\sqrt{ }$ & & & & 25,27 & 27 \\
\hline Volume/salt depletion & $\sqrt{ }$ & & & 45 & & \\
\hline Diabetes & $\sqrt{ }$ & $\sqrt{ }$ & 38,39 & 37 & 40 & 40 \\
\hline Hypertension & & $\sqrt{ }$ & & 9 & & \\
\hline Aging & $\sqrt{ }$ & & 32 & & 33 & 33 \\
\hline Anemia & $\sqrt{ }$ & & & 48 & & \\
\hline Renovascular disease & $\sqrt{ }$ & $\sqrt{ }$ & 23,63 & & & 18 \\
\hline Urine outflow obstruction & $\sqrt{ }$ & & 49 & & & \\
\hline Transplanted kidney & & $\sqrt{ }$ & & & & $46^{\mathrm{a}}$ \\
\hline
\end{tabular}

${ }^{\text {a }}$ Conflicting data by BOLD MRI in humans [47].

Thus, to summarize, renal 'physiologic' hypoxia that normally exists at certain regions is aggravated in a host of clinical conditions that predispose to the evolution of chronic kidney disease. The mechanisms that reduce renal oxygenation in CKD are summarized in table 1 (modified from Nangaku [50]). Table 2 illustrates existing evidence for renal parenchymal hypoxia under a variety of clinical and experimental conditions of CKD.

\section{Renal Hypoxia Response: Bad and Good Components}

Renal hypoxia leads both to desired and undesired effects that in most cases perpetuate the progression of CKD through an ongoing vicious circle. As shown in figure 3, the two main initiating factors are hypoxia and ROS, induced during hypoxia. These initiating proceedings trigger transcription factors, HIF and non-HIF, and a host of effectors classified as harmful or protective mediators with regard to the general outcome from the renal perspective. Their action culminates in a list of subsequent physiopathologic processes that participate in the progression of CKD. Among the harmful effectors are the renin-angiotensin-aldosterone axis, endothelin, plasmin-activator inhibitor-I, adhesion molecules and growth factors which, triggered by hypoxia, induce endothelial dysfunction, vasoconstriction, microvascular depletion, inflammation, fibrosis and tubular and glomerular dam-

Renal Parenchymal Hypoxia, Hypoxia

Response and Progression of CKD age. These effects perpetuate the vicious circle of ongoing hypoxia and progressive renal damage.

Against them rise hypoxia-triggered protective effectors, many of them HIF-dependent, such as erythropoietin and vascular endothelial growth factor (VEGF), which somewhat counteract the effect of the harmful pathways, promoting angiogenesis, improving tissue oxygenation and cell survival, and facilitating homing of progenitor cells [51]. Indeed, rats with chronic tubulointerstitial disease [28] or diabetes $[40,52]$ have shown unexpected resistance to acute hypoxic insults, conceivably through hypoxia tolerance, induced by HIF-mediated pathways. However, it is noteworthy that diabetic kidneys subjected to extreme hypoxic conditions, such as warm ischemia-reflow [53] or ex vivo perfusion with red cell-free perfusate [52], are highly vulnerable to hypoxic damage, suggesting that HIF-mediated reno-protection is ineffective beyond a 'window of opportunity' of moderate acute hypoxic stress [54].

The gross distinction between the harmful and protective effectors is not always easily done. It may depend to large extent upon the intensity and persistency of their expression and on the concomitant action of other mediators. Some may have dual actions: for instance nitric oxide synthase isoforms mediate vasodilation, but also lead to the formation of peroxynitrite. Even VEGF, generally considered renoprotective, may after all not be fully so, as evidenced by a human genotype characterized by enhanced VEGF expression, associated with a higher rate of end- 


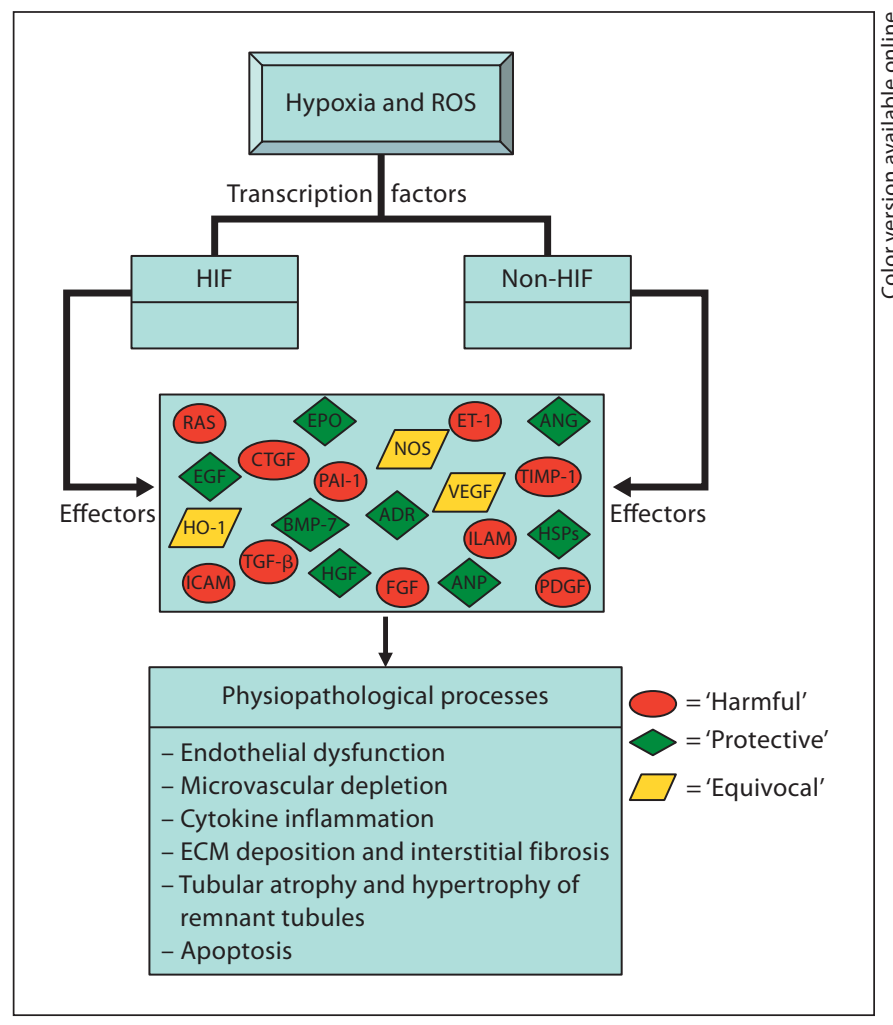

Fig. 3. Schematic presentation of hypoxia-driven renal parenchymal destructive processes and their related mediators. Key regulation of these processes may occur through HIF and non-HIF mechanisms, such as p53 or STAT3. Effectors can roughly be divided into protective and destructive mediators, and to some with both potentially injurious and protective characteristics. This is a simplistic and partial scheme only, and evidence for the association of hypoxia and reactive oxygen species (ROS) and these individual effectors and pathophysiologies is often incomplete or speculative.

stage renal disease [55]. The complex associations of the various effectors with kidney hypoxia have recently been detailed in depth by Norman and Fine [51].

In the perspective of the compound structure of the kidney and its vasculature, evaluating the precise location of an upregulated system is highly important. For instance, hyperglycemia/hypoxia-related induction of endothelin precursors and their regulator, endothelinconverting enzyme-1, is associated with the induction of endothelin- $\mathrm{ET}_{\mathrm{B}}$ receptors in the vasa recta and peritubular capillaries [56]. It is noteworthy that $\mathrm{ET}_{\mathrm{B}}$ receptors mediate endothelin-induced vasodilatation [57]. Thus, induction of a most potent vasoconstrictor is coupled with localized activation of a counterbalancing system that maintains medullary oxygenation.

\section{Therapeutic Implications}

Interventions that were found to attenuate progressive CKD evidently may relieve renal parenchymal hypoxia. The importance of blocking the renin-angiotensin system is underscored by improved medullary oxygenation following the administration of AII receptor blockade [21]. Indeed, the renal protective effects of these agents lie far beyond the mere correction of hypertension and the attenuation of proteinuria $[58,59]$. The correction of anemia is of utmost importance in the attenuation of the progression of CKD, and so is the control of glucose levels in the prevention of progressive diabetic nephropathy. Plausibly, a low salt and protein diet attenuates enhanced GFR and transport activity in the remaining nephrons and may prevent subsequent tissue hypoxia. The potential benefit of selective manipulation of hypoxia renoprotective adaptive responses has also been suggested. Indeed, intrinsic HIF upregulation in experimental CKD and in the diabetic kidney seemingly confers protection against acute hypoxic insults $[28,40]$, and the individual impact of exogenous erythropoietin, one of the major renoprotective HIF-target genes, in delaying the progression of CKD has been suggested in experimental and clinical settings, probably regardless of the correction of anemia $[60,61]$. It is tempting to assume that upstream enhancement of HIF by specific inhibitors of prolyl hydroxylases may attenuate the progression of CKD [50,51], as it seemingly reduces kidney injury in acute settings [62]. However, caution is warranted since such an intervention on a chronic basis might activate undesired genes as well.

In conclusion, renal hypoxia does occur throughout the progression of CKD as has been shown by a variety of methods; it is multi-factorial and conceivably plays a role in CKD progression. The kidney responds to declining ambient oxygenation by the activation of genes providing adaptation and endurance, as well as with the induction of pathways with a potential destructive nature. Through the later responses, a vicious circle develops with enhanced fibrosis and microvascular depletion, and subsequent hypoxia and progressive kidney damage.

The significance of the mechanisms of renal hypoxia and hypoxic response in the diseased kidney should be further elucidated by interventional studies. This may help us in the development of therapeutic interventions, intensifying protective mechanisms and eliminating maladaptive responses. 


\section{References}

-1 Brenner BM, Meyer TW, Hostetter TH: Dietary protein intake and the progressive nature of kidney disease: the role of hemodynamically mediated glomerular injury in the pathogenesis of progressive glomerular sclerosis in aging, renal ablation, and intrinsic renal disease. N Engl J Med 1982;307:652659.

$\checkmark 2$ Dunn BR, Anderson S, Brenner BM: The hemodynamic basis of progressive renal disease. Semin Nephrol 1986;6:122-138.

-3 Schainuck LI, Striker GE, Cutler RE, Benditt EP: Structural-functional correlations in renal disease. II. The correlations. Hum Pathol 1970;1:631-641.

4 Remuzzi G, Bertani T: Pathophysiology of progressive nephropathies. N Engl J Med 1998;339:1448-1456.

5 Parmar MS: Strategies to Retard Progression of Chronic Kidney Disease. MKSAP in Nephrology and Hypertension, ed 2. 1998. http://www.uninet.edu/cin2002/html/conf/ parmar/parmar.html.

-6 Fine LG, Bandyopadhay D, Norman JT: Is there a common mechanism for the progression of different types of renal diseases other than proteinuria? Towards the unifying theme of chronic hypoxia. Kidney Int 2000 57(suppl 75):S22-S26.

7 Brezis M, Rosen S: Hypoxia of the renal medulla - its implications for disease. N Engl J Med 1995;332:647-655.

8 O'Connor PM: Renal oxygen delivery: matching delivery to metabolic demand. Clin Exp Pharmacol Physiol 2006;33:961967.

-9 Rosenberger C, Rosen S, Heyman SN: Renal parenchymal oxygenation and hypoxia adaptation in acute kidney injury. Clin Exp Pharmacol Physiol 2006;33:980-988.

-10 Welch WJ, Baumgartl H, Lubbers D, Wilcox CS: Nephron $\mathrm{PO}_{2}$ and renal oxygen usage in the hypertensive rat kidney. Kidney Int 2001, 59:230-237.

-11 Heyman SN, Brezis M, Epstein FH, Spokes K, Silva P, Rosen S: Early renal medullary hypoxic injury from radiocontrast and indomethacin. Kidney Int 1991;40:632-642.

-12 Agmon Y, Brezis M: Effects of nonsteroidal anti-inflammatory drugs upon intrarenal blood flow: selective medullary hypoperfusion. Exp Nephrol 1993;1:357-363.

$\checkmark 13$ Haase VH: Hypoxia-inducible factors in the kidney. Am J Physiol Renal Physiol 2006;291: F271-F281

14 Maxwell P: HIF-1: an oxygen response system with special relevance to the kidney. J Am Soc Nephrol 2003;14:2712-2722.

-15 Rosenberger C, Rosen S, Heyman S: Current understanding of HIF in renal disease. Kidney Blood Press Res 2005;28:325-340.
16 Bachmann S, Le Hir M, Eckardt KU: Colocalization of erythropoietin mRNA and ecto-5'-nucleotidase immunoreactivity in peritubular cells of rat renal cortex indicates that fibroblasts produce erythropoietin. J Histochem Cytochem 1993;41:335-341.

17 Rosenberger C, Mandriota S, Jurgensen JS, Wiesener MS, Horstrup JH, Frei U, Ratcliffe PJ, Maxwell PH, Bachmann S, Eckardt KU: Expression of hypoxia-inducible factor-1alpha and -2alpha in hypoxic and ischemic rat kidneys. J Am Soc Nephrol 2002;13:17211732.

18 Rosenberger C, Griethe W, Gruber G, Wiesener MS, Frei U, Bachmann S, Eckardt KU: Cellular responses to hypoxia after renal segmental infarction. Kidney Int 2003;64: 874-886.

19 Rosenberger C, Heyman SN, Rosen S, Shina A, Gruber G, Goldfarb M, Griethe W, Frei U, Bachmann S, Eckardt KU: Up-regulation of HIF in experimental acute renal failure: Evidence for a protective transcriptional response to hypoxia. Kidney Int 2005;67:531542.

20 Rosenberger C, Goldfarb M, Shina A, Bachmann S, Frei U, Eckardt KU, Schrader T, Rosen S, Heyman SN: Evidence for sustained renal hypoxia and transient hypoxia adaptation in experimental rhabdomyolysis-induced acute kidney injury. Nephrol Dial Transpl 2008;23:1135-1143.

21 Manotham K, Ongvilawan B, Urusopone P, Chetsurakram S, Tanamai J, Limkuansuwan $\mathrm{P}$, Tungasanga K, Aiam-Ong S: Intrarenal hypoxia in CKD patients, a BOLD MRI study. J Am Soc Nephrol 2006;17:164A.

22 Norman JT, Stidwill R, Singer M, Fine LG: Angiotensin II blockade augments renal cortical microvascular $\mathrm{pO}_{2}$ indicating a novel, potentially renoprotective action. Nephron Physiol 2003;94:p39-p46.

23 Textor SC, Glockner JF, Lerman LO, Misra S, McKusick MA, Riederer SJ, Grande JP, Gomez I, Romero JC: The use of magnetic resonance to evaluate tissue oxygenation in renal artery stenosis. J Am Soc Nephrol 2008;19: 780-788.

24 Basile DP, Donohoe D, Roethe K, Osborn JL: Renal ischemic injury results in permanent damage to peritubular capillaries and influences long-term function. Am J Physiol Renal Physiol 2001;281:F887-F899.

25 Matsumoto M, Tanaka T, Yamamoto T, Noiri E, Miyata T, Inagi R, Fujita T, Nangaku M Hypoperfusion of peritubular capillaries induces chronic hypoxia before progression of tubulointerstitial injury in a progressive model of rat glomerulonephritis J Am Soc Nephrol 2004;15:1574-1581.

26 Ohashi R, Kitamura H, Yamanaka N: Peritubular capillary injury during the progression of experimental glomerulonephritis in rats. J Am Soc Nephrol 2000;11:47-56.
27 Manotham K, Tanaka T, Matsumoto M, Ohse T, Miyata T, Inagi R, Kurokawa K, Fujita T, Nangaku M: Evidence of tubular hypoxia in the early phase of the remnant kidney model. J Am Soc Nephrol 2004;15: 1277-1288.

28 Goldfarb M, Rosenberger C, Abassi Z, Shina A, Zilbersat F, Eckhardt KU, Rosen S, Heyman SN: Acute-on-chronic renal failure in the rat: functional compensation and hypoxia tolerance. Am J Nephrol 2006;26:22-33.

29 Kairaitis LK, Wang Y, Gassman M, Tay YC, Harris DC: HIF-1a expression follows microvascular loss in advanced murine adriamycin nephrosis. Am J Physiol Renal Physiol 2005;288:F198-F206.

30 Zhong Z, Arteel GE, Connor HD, Yin M, Frankenberg MV, Stachlewitz RF, Raleigh JA, Mason RP, Thurman RG: Cyclosporin A increases hypoxia and free radical production by rat kidneys: prevention by dietary glycine. Am J Physiol 1998;275:F595-F604.

-31 Yuan H-T, Li X-Z, Pitera JE, Long DA, Woolf AS: Peritubular capillary loss after mouse acute nephrotoxicity correlates with downregulation of vascular endothelial growth factor A and hypoxia-inducible factor-1a. Am J Pathol 2003;163:2289-2301.

32 Epstein FH, Prasad P: Effects of furosemide on medullary oxygenation in younger and older subjects. Kidney Int 2000;57:20802083.

33 Tanaka T, Kato H, Kojima I, Ohse T, Son D, Tawakami T, Yatagawa T, Inagi R, Fujita T, Nangaku M: Hypoxia and expression of hypoxia-inducible factor in the aging kidney. J Gerontol A Biol Sci Med Sci 2006;61: 795-805.

34 Rathaus M, Greenfeld Z, Podjarny E, Brezis M, Bernheim J: Sodium loading and renal prostaglandins in old rats. Prostaglandins Leukot Essent Fatty Acids 1993;49:815-819.

35 Baylis C: Nitric oxide deficiency in chronic kidney disease. Am J Physiol Renal Physiol 2008;294:F1-F9.

36 Adler S, Huang H, Wolin MS, Kaminski PM: Oxidant stress leads to impaired regulation of renal cortical oxygen consumption by nitric oxide in the aging kidney. J Am Soc Nephrol 2004; 15:52-60.

-37 Palm F, Cederberg J, Hansell P, Liss P, Carlsson PO: Reactive oxygen species cause diabetes-induced decrease in renal oxygen tension. Diabetologia 2003;46:1153-1160.

38 Ries M, Basseau F, Tyndal B, Jones R, Deminiere $\mathrm{C}$, Catargi $\mathrm{B}$, Combe $\mathrm{C}$, Moonen $\mathrm{CW}$, Grenier N: Renal diffusion and BOLD MRI in experimental diabetic nephropathy. Blood oxygen leveled pendent. J Magn Reson Imaging 2003;17:104-113.

39 Epstein FH, Veves A, Prasad PV: Effect of diabetes on renal medullary oxygenation during water diuresis. Diabetes Care 2002; 25:575-578. 
40 Rosenberger C, Khamaisi M, Abassi Z, Weksler-Zengen S, Goldfarb M, Shilo V, Shina A, Zilbertrest F, Eckhardt KW, Rosen S, Heyman SN: Adaptation to hypoxia in the diabetic rat kidney. Kidney Int 2008;73:3442 .

-41 Katavetin P, Miyata T, Inagi R, Tanaka T, Sassa R, Ingelfinger JR, Fujita T, Nangaku M: High glucose blunts vascular endothelial growth factor response to hypoxia via the oxidative stress-regulated hypoxia-inducible factor/hypoxia-responsible element pathway. J Am Soc Nephrol 2006;17:14051413.

-42 Palm F: Intrarenal oxygen in diabetes and a possible link to diabetic nephropathy. Clin Exp Pharmacol Physiol 2006;33:997-1001.

43 Palm F, Friederich M, Carlsson PO, Hansell $\mathrm{P}$, Teerlink T, Liss P: Reduced nitric oxide in diabetic kidneys due to increased hepatic arginine metabolism: implications for renomedullary oxygen availability. Am J Physiol Renal Physiol 2008;294:F30-F37.

44 Welch WJ: Intrarenal oxygen and hyperten sion. Clin Exp Pharmacol Physiol 2006;33: 1002-1005.

-45 Stillman LE, Brezis M, Heyman SN, Epstein FH, Spokes K, Rosen S: Effects of salt depletion on the kidney: changes in medullary oxygenation and thick ascending limb size. J Am Soc Nephrol 1994;4:1538-1545.

-46 Rosenberger C, Pratschke J, Rudolph B, Rosen S, Heyman SN, Babel N, Schindler R, Eckhardt KW, Frei U, Reinke P: Immunohistochemical detection of hypoxia-inducible factor-1alpha in human renal allograft biopsies. J Am Soc Nephrol 2007;18:343-351.

-47 Sadowski EA, Fain SB, Alford SK, Korosec FR, Fine J, Muehrer R, Djamali A, Hofmann RM, Becker BN, Grist TM: Assessment of acute renal transplant rejection with blood oxygen level-dependent MR imaging: initial experience. Radiology 2005;236:911-919.
48 Johannes T, Mik EG, Nohe B, Unertl KE, Ince $\mathrm{C}$ : Acute decrease in renal microvascular $\mathrm{PO}_{2}$ during acute normovolemic hemodilution. Am J Physiol Renal Physiol 2007;292: F796-F803.

-49 Pedersen M, Dissing TH, Morkenborg J, Stodkilde-Jorgensen H, Hansen LH, Pedersen LB, Grenier N, Frokiaer J: Validation of quantitative BOLD MRI measurements in kidney: application to unilateral ureteral obstruction. Kidney Int 2005;67:2305-2312.

50 Nangaku M: Chronic hypoxia and tubulointerstitial injury: a final common pathway to end-stage renal failure. J Am Soc Nephrol 2006; 17:17-25.

51 Norman JT, Fine LG: Intrarenal oxygenation in chronic renal failure. Clin Exp Pharmacol Physiol 2006;33:989-996.

52 Rosenberger C, Goldfarb M, Khamaisi M, Shina A, Shilo V, Rosen S, Heyman SN: Acute kidney injury in the diabetic rat: studies in the isolated perfused and intact kidney. Am J Nephrol 2008;28:831-839.

53 Melin J, Hellberg O, Fellstrom B: Hyperglycaemia and renal ischaemia-reperfusion injury. Nephrol Dial Transplant 2003;18:460462.

54 Rosenberger C, Shina A, Rosen S, Goldfarb M, Eckardt K, Heyman SN: Hypoxia inducible factors and tubular cell survival in isolated perfused kidneys. Kidney Int 2006;70: 60-70.

55 Doi K, Noiri E, Nakao A, Fujita T, Kobayashi S, Tokunaga K: Functional polymorphisms in the vascular endothelial growth factor gene are associated with development of end-stage renal disease in males. J Am Soc Nephrol 2006;17:823-830.
6 Khamaisi M, Raz I, Shilo V, Shina A, Rosenberger C, Dahan R, Abassi Z, Meidan R, Lecht S, Heyman SN: Diabetes and radiocontrast media increase endothelin converting enzyme-1 in the kidney. Kidney Int 2008; 74:91-100.

57 Gurbanov K, Rubinstein I, Hoffman A, Abassi Z, Better O, Winaver J: Differential regulation of renal regional blood flow by endothelin-1. Am J Physiol 1996;271:F1166F1172.

58 Izuhara Y, Nangaku M, Inagi R, Tominaga N, Aizawa T, Kurokawa K, van Ypersele de Strihou C, Miyata T: Renoprotective properties of angiotensin receptor blockers beyond blood pressure lowering. J Am Soc Nephrol 2005;16:3631-3641.

59 Rüster C, Wolf G: Renin-angiotensin-aldosterone system and progression of renal disease. J Am Soc Nephrol 2006;17:2985-2991.

60 Gouva C, Nikolopoulos P, Ioannidis JP, Siamopoulos KC: Treating anemia early in renal failure patients slows the decline of renal function: a randomized controlled trial. Kidney Int 2004;66:753-760.

61 Bahlmann FH, Song R, Boehm SM, et al: Low-dose therapy with the long-acting erythropoietin analogue darbepoetin alpha persistently activates endothelial Akt and attenuates progressive organ failure. Circulation 2004;110:1006-1012.

62 Bernhardt W, Câmpean V, Kany S, Jürgensen JS, Weidemann A, Warnecke C, Arend M, Klaus S, Günzler V, Amann K, Willam C, Wiesener M, Eckardt KU: Preconditional activation of hypoxia-inducible factors ameliorates ischemic acute renal failure. J Am Soc Nephrol 2006;17:1970-1978.

-63 Juillard L, Lerman LO, Kruger DG, Haas JA, Rucker BC, Polzin JA, Riederer SJ, Romero JC: Blood oxygen level-dependent measurement of acute intra-renal ischemia. Kidney Int 2004;65:944-950. 